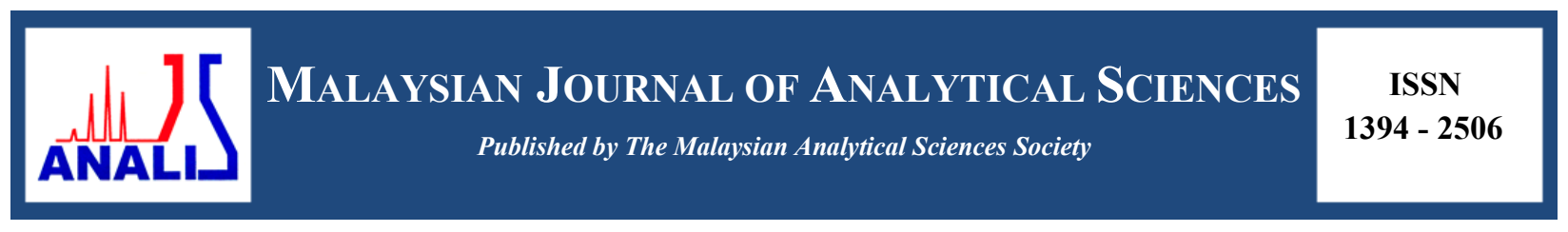

\title{
STUDY ON THE EFFECT OF OIL PHASE AND CO-SURFACTANT ON MICROEMULSION SYSTEMS
}

\author{
(Kajian Kesan Fasa Minyak dan Ko-Surfaktan Terhadap Sistem Mikroemulsi) \\ Muhammad Asri Abd Sisak ${ }^{1}$, Rusli Daik ${ }^{1,2}$, Suria Ramli ${ }^{1,2 *}$ \\ ${ }^{I}$ School of Chemical Sciences and Food Technology \\ ${ }^{2}$ Polymer Research Center \\ Faculty of Science and Technology, \\ Universiti Kebangsaan Malaysia, 43600 UKM Bangi, Selangor, Malaysia \\ *Corresponding author: su_ramli@ukm.edu.my
}

Received: 28 September 2016; Accepted: 6 March 2017

\begin{abstract}
The purpose of the present study was to investigate the effect of different oil and chain lengths of co-surfactant on microemulsion region. Oleic acid and isopropyl myristate were used as the oil phase, transcutol, polyethylene glycol 400 (PEG 400) and propylene glycol as co-surfactant and Brij 97 as a surfactant. From the ternary phase diagrams, isopropyl myristate based system is more feasible oil phase to formulate microemulsion compared to oleic acid based system. Moreover, transcutol (medium chain length) is the most suitable co-surfactant to blend with a single-chain surfactant, Brij 97 in order to have a high stability and a large area of microemulsion region.
\end{abstract}

Keywords: microemulsion, oleic acid, isopropyl myristate, transcutol, propylene glycol

\begin{abstract}
Abstrak
Kajian ini bertujuan untuk mengkaji kesan minyak yang berbeza dan panjang rantai ko-surfaktan terhadap rantau mikroemulsi. Asid oleik dan isopropil miristat telah digunakan sebagai fasa minyak, transcutol, polietilena glikol 400 (PEG 400) dan propilena glikol sebagai ko-surfaktan dan Brij 97 sebagai surfaktan. Berdasarkan rajah fasa tenari, sistem berasaskan isopropil miristat adalah fasa minyak yang lebih sesuai untuk membentuk mikroemulsi berbanding sistem berasaskan asid oleik. Selain itu, transcutol yang berantai sederhana panjang adalah ko-surfaktan yang sesuai untuk diformulasikan bersama surfaktan rantai tunggal, Brij 97 yang memberikan rantau kawasan mikroemulsi yang besar dengan kestabilan yang tinggi.
\end{abstract}

Kata kunci: mikroemulsi, asid oleik, isopropil miristat, transcutol, propilena glikol

\section{Introduction}

Microemulsions are versatile systems and can be used in various applications such as for cutting oils, corrosion inhibitors, biotechnology, fuels, coating and textile finishing, food industries, lubricants, and also in pharmaceuticals [1]. Microemulsions have generated extensive interest over the years as potential drug delivery systems, especially for the delivery of the hydrophilic and lipophilic drug [2]. It is because of its several characteristics such as improved drug solubilization, longer shelf life, ease of preparation and improvement of bioavailability of poorly soluble drugs [3]. It is also can be used to deliver drugs via several routes and making them as a promising dermal delivery of the drug through an efficient route of drug administration [4]. 
The idea of microemulsion was introduced by Hoar and Schulman as early as the 1940s where they successfully obtained a clear single-phase solution by titrating a milky emulsion with hexanol [5]. That discovery is still used until now even after seven decades had passed. In general, microemulsion is a colloidal dispersion composed of three or four components which are the oil phase, an aqueous phase, surfactant and co-surfactant at applicable ratios. It is a single optically isotropic and thermodynamically or homogeneously stable liquid solution with a nanodroplet diameter $[1,6]$. Microemulsion systems formed spontaneously and have low viscosity which behaves as a Newtonian liquid [4]. Microemulsion has been shown to have an ultra low interfacial tension as it can load a large fraction of surfactant/co-surfactant mixture at interface thus thermodynamically stable [7]. Globule size of stable microemulsions is usually within the range of $10-100 \mathrm{~nm}\left(100-1000^{\circ} \mathrm{A}\right)$ therefore the whole system is transparent and the globules became invisible to the naked eye due to the fact that dispersed phase droplet does not refract the light [8]. The size of the droplets makes the term of 'microemulsion' is misleading while these systems are actually nano-sized emulsions [1].

Microemulsion is easy to develop and require a low energy contribution during preparation to form a thermodynamic stability, however, it depends on each of the components. This paper will focus on the effect of the oil phase and co-surfactant to the microemulsion system. The oil phase is the most important excipients in the formulation since it governs the selection of the other ingredients for the microemulsion and there are two main factors that need be considered before selecting the appropriate oil phase. The first one is the capability of the oil in solubilizing the active pharmaceutical ingredient (API). Second, the chosen must be such that can result in the large existence area of the microemulsion. Oils with shorter hydrocarbon chains are more facile to form a microemulsion as compared to oils with long hydrocarbon chains. Meanwhile, an oil potentiality to solubilize lipophilic groups is directly proportional to the chain length of the oil [1]. The most common esters used and act as a permeation enhancer in formulations which is isopropyl myristate, IPM $\left(\mathrm{C}_{17} \mathrm{H}_{34} \mathrm{O}_{2}\right)$ and also an unsaturated $\mathrm{C} 18$ alkyl chain, oleic acid, $\mathrm{OA}\left(\mathrm{C}_{18} \mathrm{H}_{34} \mathrm{O}_{2}\right)$ are frequently used in microemulsion formulations.

Microemulsions can be formulated using single-chain surfactants or double chain surfactants. Single chain surfactants do not lower the oil-water interfacial tension sufficiently and hence cosurfactants are required [9]. Cosurfactant accumulates substantially at interface layer, increasing the fluidity of interfacial film by penetrating into the surfactant layer. The presence of co-surfactants contributes the interfacial film sufficient flexibility to take up different curvatures required to form a microemulsion over a wide range of composition. If a single surfactant film is desired, the lipophilic chains of the surfactant should be sufficiently short or contain fluidizing groups (e.g. unsaturated bonds). Short to medium chain length alcohols (C3-C8) are commonly added as co-surfactants which further reduce the interfacial tension and increase the fluidity of the interface [1]. The roles of a co-surfactant are to increase the fluidity of the interface, destroy liquid crystalline or gel structure which would prevent the formation of the microemulsion and adjust the HLB value and spontaneous curvature of the interface by changing surfactant partitioning characteristic [4].

In this preliminary study, our aim is to identify the effect of oil and chain lengths of co-surfactant in resulting a large area of the microemulsion region by using oleic acid and IPM as the oil phase, and various co-surfactant, which are transcutol, PEG 400, and propylene glycol.

\section{Materials and Methods}

Oleic acid (OA) was obtained from Bendosen Laboratory Chemical. Isopropyl myristate (IPM) was purchased from Friedemann Schmidt Chemical. Brij 97 (polyoxyethylene-10-oleyl ether), propylene glycol (PG), transcutol (diethylene glycol monoethyl ether), polyethylene glycol 400 (PEG400) were obtained from Sigma-Aldrich Chemical Co. Deionized water was used throughout the experiments. All other chemicals utilize in the experiments were analytical grade.

\section{Construction of pseudo-ternary phase diagrams}

The pseudo-ternary phase diagrams of oil, surfactant, co-surfactant and water were constructed using water titration method to obtain the components and their appropriate ratio which can result to the large existence area of the microemulsion. In brief, the graph was constructed based on water dilution lines, which represent increasing water content and, thus, decreasing a surfactant-cosurfactant concentration. The oils employed in the present study were 
oleic acid and IPM. A non-ionic surfactant (Brij 97) was mixed with various co-surfactant (transcutol, propylene glycol, and PEG-400) at a weight ratio of $\mathrm{K}_{\mathrm{m}} 1: 1, \mathrm{~K}_{\mathrm{m}} 2: 1$, or $\mathrm{K}_{\mathrm{m}} 3: 1$ to obtain surfactant and co-surfactant mixture, $\mathrm{S} / \mathrm{CoS}\left(\mathrm{K}_{\mathrm{m}}\right)$. Aliquots of each $\mathrm{S} / \mathrm{CoS}$ were then mixed with oil at room temperature $\left(25{ }^{\circ} \mathrm{C}\right)$. For each phase diagram, the ratio of oil to the $\mathrm{S} / \mathrm{CoS}$ was varied as 1:9, 2:8, 3:7, 4:6, 5:5, 6:4, 7:3, 8:2, 9:1 (w/w) and the resulting mixtures were subsequently titrated with water under vigorous stirring with a vortex mixer at room temperature. After equilibrium, the samples were visually checked and determined as being clear microemulsions, or emulsions, or gels. The samples were marked as points in the phase diagram. The area covered by these points was considered as the microemulsion region of existence. Quantities of all three phases were taken in $\% \mathrm{w} / \mathrm{w}$.

\section{Polarized light microscopy}

Visual inspection was first made after each addition of water to the oil and surfactant and co-surfactant mixture. The samples were identified as microemulsions when they appear as transparent/translucent and easily flowable liquid. The samples were identified as emulsions when they appeared as milky or turbid liquids. The samples were identified as a gel when they did not show a change in the meniscus after tilting to an angle of $90^{\circ}$. Then, the microemulsion samples were verified their isotropic nature under cross-polarizes light microscopy from the image performed. It is expected that the isotropic substance like microemulsion will not reflect the polarized light and the image viewed will remain dark [10].

\section{Construction of pseudo-ternary phase diagrams}

\section{Results and Discussion}

Pseudo-ternary plot identifies phase boundaries and distinct regions of the ternary mixture (oil, water, surfactant/cosurfactant) where it may exist as biphasic or monophasic, non-isotropic, or liquid crystalline in nature and co-existed in a state of dynamic equilibrium. When four or more components are used pseudo-ternary phase diagrams are used to depict these systems in which each corner represents binary mixtures of two components such as surfactant/co-surfactant, surfactant/water, oil/drug, and water/drug mixtures [1,11]. Each corner of the ternary phase diagram represents $100 \%$ concentrations of a particular component [12].

Three types of system combinations (Brij 97/PEG400/Water, Brij 97/PG/Water, and Brij 97/Transcutol/Water) were developed with specific ratios of $\mathrm{S} / \mathrm{CoS}\left(\mathrm{K}_{\mathrm{m}}=1: 1,2: 1\right.$, and 3:1). Two common oil phase used in these systems are oleic acid and isopropyl myristate. Study of the ternary phase diagrams was done to investigate the effect of OA and IPM with the various mixtures of $\mathrm{S} / \mathrm{CoS}$ on the formation of the stable microemulsion.

\section{Effect of OA and IPM on the system of Brij 97/PEG 400/Water}

The pseudo-ternary phase diagrams of the Brij 97/PEG 400/Water system using OA and IPM as the oil phase were shown in Figure 1 and 2 where the shaded region represents the microemulsion region. IPM (molecular volume $528.2 \mathrm{~g} / \mathrm{cm}^{3}$ ) based microemulsion system showed a smaller area of microemulsion as compared to a system based on OA (molecular volume $523.9 \mathrm{~g} / \mathrm{cm}^{3}$ ). This result is in accordance with literature reported by [13] that also indicate the smaller area of microemulsion region when used PEG 400 as a co-surfactant, IPM as an oil phase and Brij 30/Brij 35 (HLB 11.1) as a surfactant. Meanwhile, the result of OA based system is in good agreement with the previous study conducted by [14] that shows stable microemulsion system consisting of oleic acid (oil phase), Tween 20 (surfactant), PEG 400 (co-surfactant), water (aqueous phase). These results might be due to the fact that the lower the molecular volume of oils, the greater the surfactant efficiency [15]. In terms of ratio, $\mathrm{K}_{\mathrm{m}} 1: 1$ of oleic acid based system give a larger region compare to $\mathrm{K}_{\mathrm{m}} 2: 1$ and $\mathrm{K}_{\mathrm{m}}$ 3:1. The further increment of surfactant concentration i.e. $\mathrm{S} / \mathrm{CoS}$ ratio $\mathrm{K}_{\mathrm{m}} 2: 1$ (Figure $1 \mathrm{~b}$ ) and $\mathrm{K}_{\mathrm{m}}$ 3:1 (Figure $1 \mathrm{c}$ ) appeared to have a destabilizing effect on the formation of the microemulsion and led to considerable reduction in microemulsion area. It might be due to insufficient co-surfactant concentration, required to reduce the interfacial tension and provide the flexibility of the interfaces [15]. Both systems show the lower concentration of water except for the phase diagram in Figure 1(a). This might be due to the inversion phase from w/o to o/w system, where a number of liquid crystalline phase are considered as possible intermediates during the process [16]. For those systems that remain clear at higher concentration of water are expected to be the o/w phase with low percentage of oil in the system. 


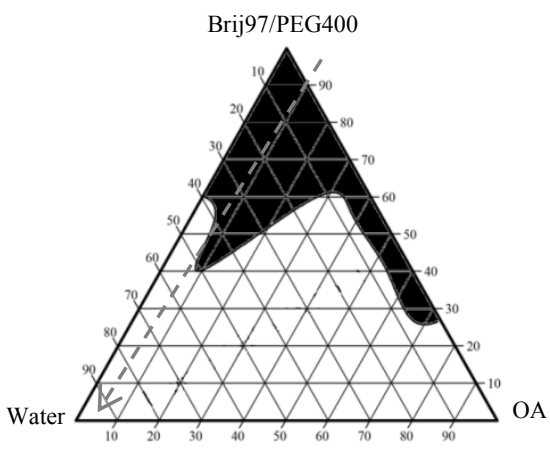

(a)

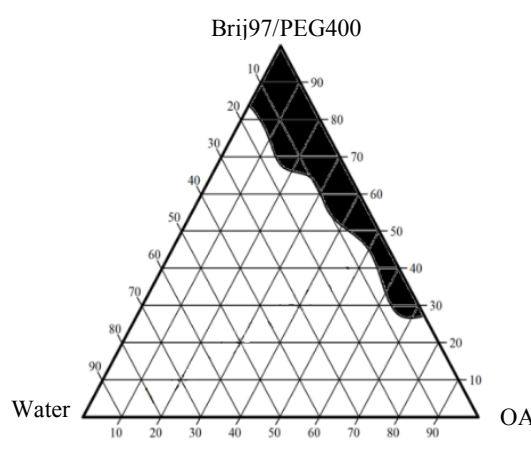

(b)

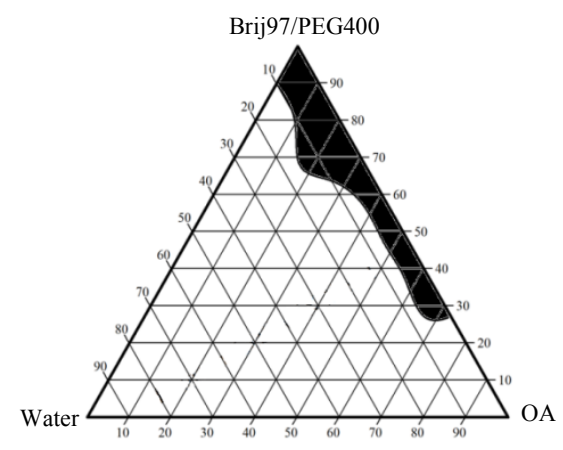

(c)

Figure 1. Pseudo-ternary phase diagrams composed of OA/Brij=97/PEG400/water(a) $K_{m} 1: 1$, (b) $K_{m} 2: 1$ and (c) $K_{m}$ $3: 1$. The shaded region is microemulsion area and $(--\rightarrow)$ water dilution line.

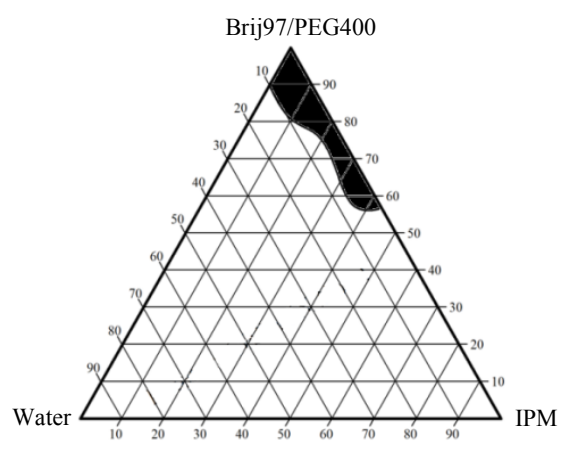

(a)

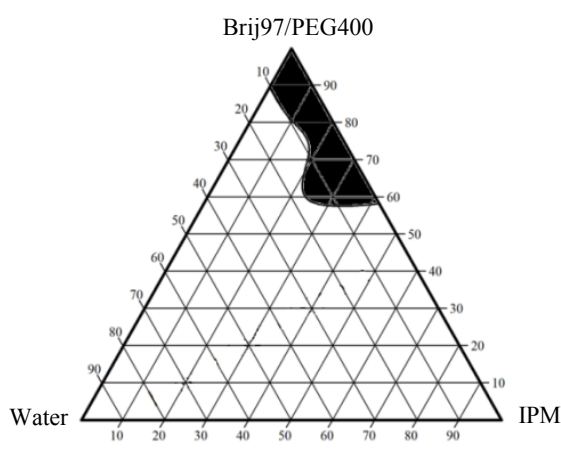

(b)

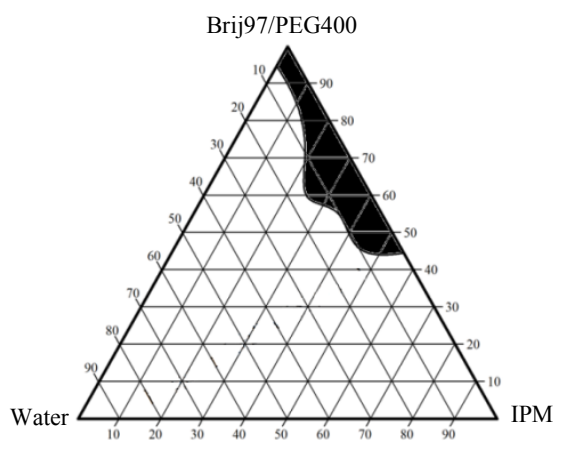

(c)

Figure 2. Pseudo-ternary phase diagrams composed of IPM/Brij 97/PEG400/water (a) $\mathrm{K}_{\mathrm{m}} 1: 1$, (b) $\mathrm{K}_{\mathrm{m}} 2: 1$ and (c) $\mathrm{K}_{\mathrm{m}} 3: 1$

\section{Effect of OA and IPM on the system of Brij 97/PG/Water}

These systems contain PG as a co-surfactant which is a short chain of co-surfactant. The results in Figure 3 and 4 shows that IPM based system give the bigger area of microemulsion region compared to OA based system. This result is similar to the study conducted by Abd-Allah et al. [16] where the clear microemulsion region was from 10 to $30 \mathrm{wt} . \%$ of water content in OA based system and when further dilution with the amount of water, resulting in the formation of a gel. This result also ascribed to the large molecular weight, MW of OA $(\mathrm{MW}=282.46 \mathrm{~g} / \mathrm{mol})$ compared to IPM (MW = $270.45 \mathrm{~g} / \mathrm{mol})$ which is not favored to the formation of microemulsion [16]. For IPM based system, $\mathrm{K}_{\mathrm{m}}$ 1:1 give the highest concentration of water content (95 wt. \%) at a ratio of oil to $\mathrm{S} / \mathrm{CoS} 1: 9$. However, at $\mathrm{K}_{\mathrm{m}} 2: 1$ and $\mathrm{K}_{\mathrm{m}} 3: 1$, the region of microemulsion become smaller because of increasing concentration of Brij 97 make the interfacial tension unstable. This is probably due to an inadequate amount of co-surfactant to assist surfactant in lowering the interfacial tension. Furthermore, using propylene glycol in the microemulsion system, increase viscosity and hence gives the high possibility of the gel formation [17]. 


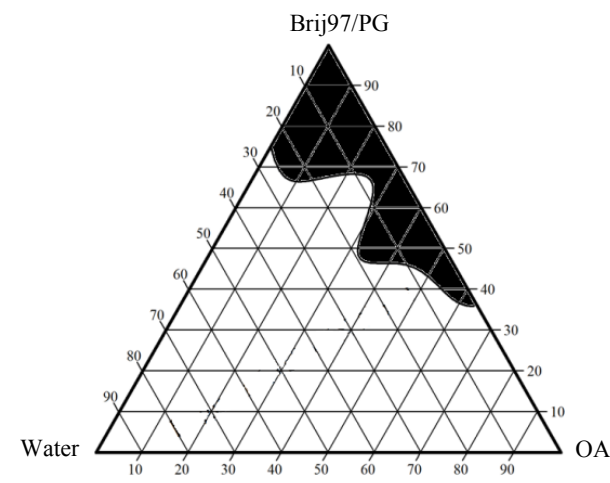

(a)

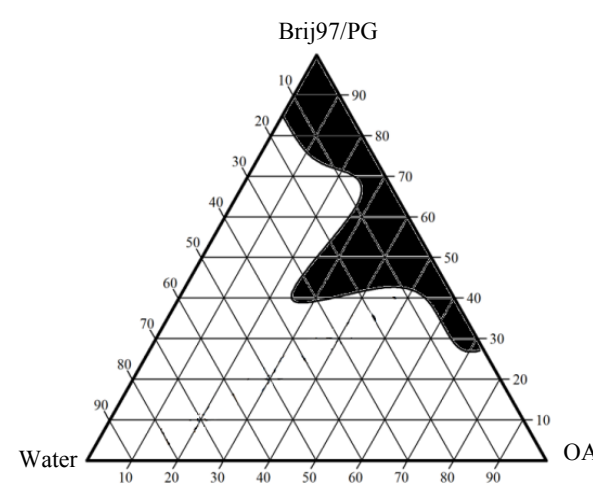

(b)

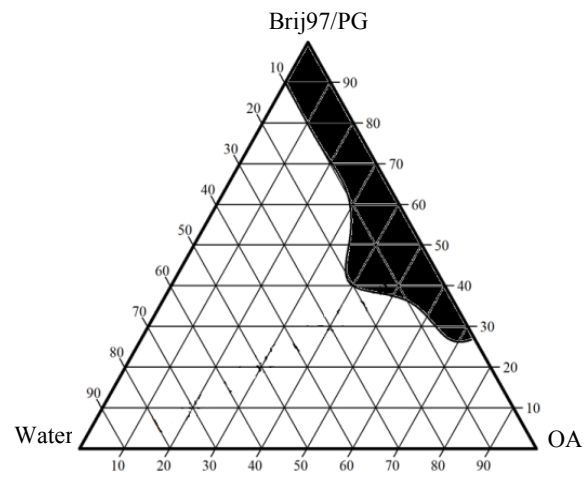

(c)

Figure 3. Pseudo-ternary phase diagrams composed of OA/Brij 97/PG/water (a) $\mathrm{K}_{\mathrm{m}} 1: 1$, (b) $\mathrm{K}_{\mathrm{m}} 2: 1$ and (c) $\mathrm{K}_{\mathrm{m}} 3: 1$

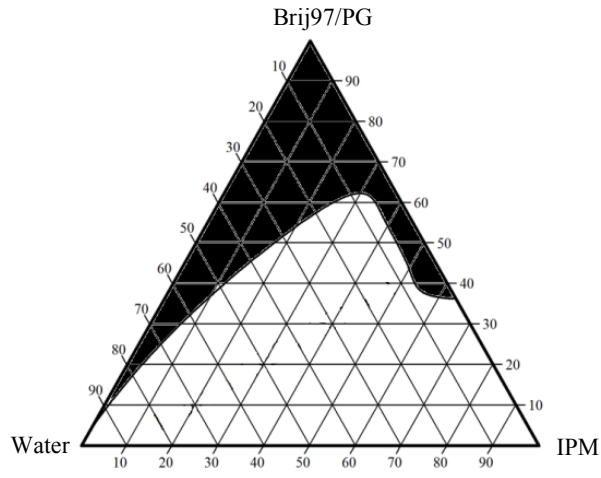

(a)

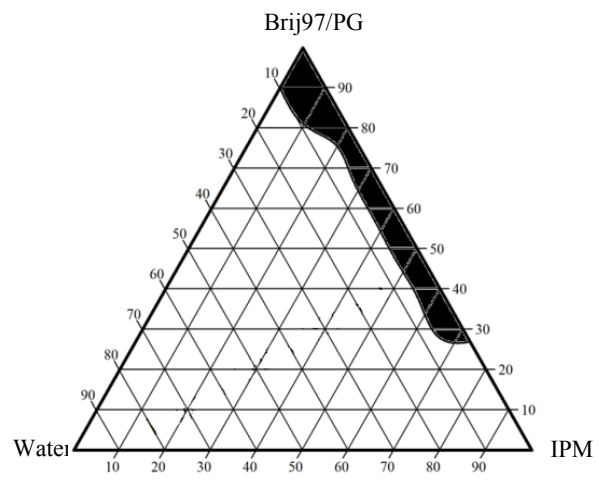

(b)

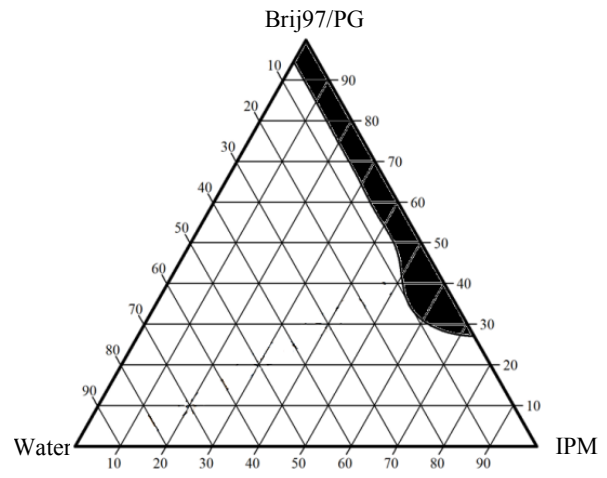

(c)

Figure 4. Pseudo-ternary phase diagrams composed of IPM/Brij 97/PG/water (a) $\mathrm{K}_{\mathrm{m}} 1: 1$, (b) $\mathrm{K}_{\mathrm{m}} 2: 1$ and (c) $\mathrm{K}_{\mathrm{m}} 3: 1$

\section{Effect of OA and IPM on the system of OA/Brij 97/Transcutol/Water}

Transcutol is a medium chain length act as a co-surfactant and frequently proposed as less irritant and alternatives to the medium chain alcohols [18]. The region of microemulsion using transcutol as a co-surfactant form bigger area comparable to PEG 400 and PG for both oleic acid and IPM based formulation as shown in Figure 5 and 6 . The best result is still favored to IPM based formulation where both $K_{m} 1: 1$ and $K_{m} 2: 1$ give the highest concentration of water (95 wt.\%) at ratio oil to $\mathrm{S} / \mathrm{CoS} 1: 9$. This result attributable to the function of medium chain length alcohols which can increase the flexibility of the hydrocarbon tail and also allow better penetration of the oil into the region of hydrocarbon. In addition, the solubility properties of aqueous and oil phases could also be increased by medium chain length alcohols due to their partitioning behavior between the two phases. [12]. 


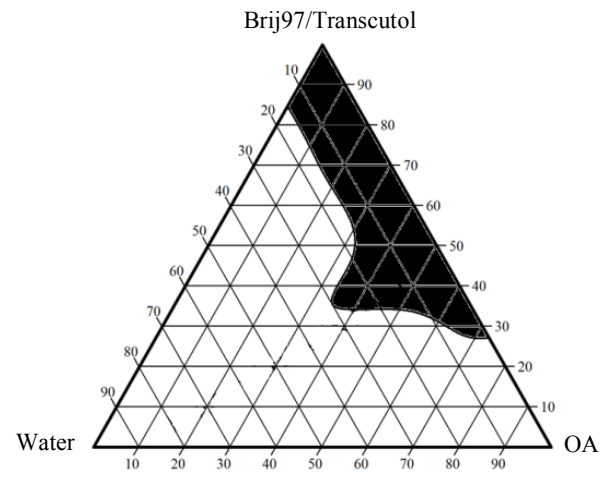

(a)

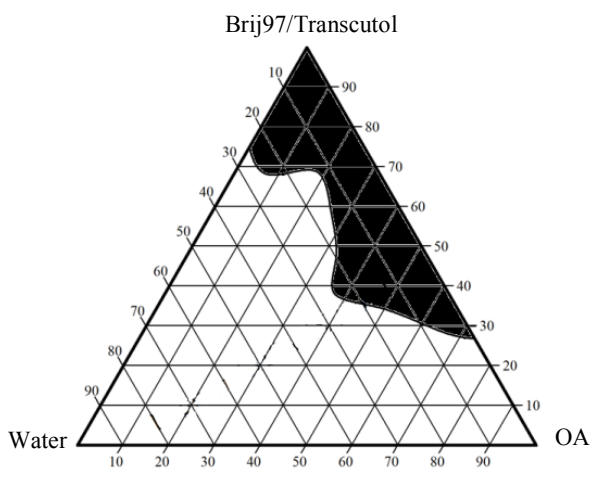

(b)

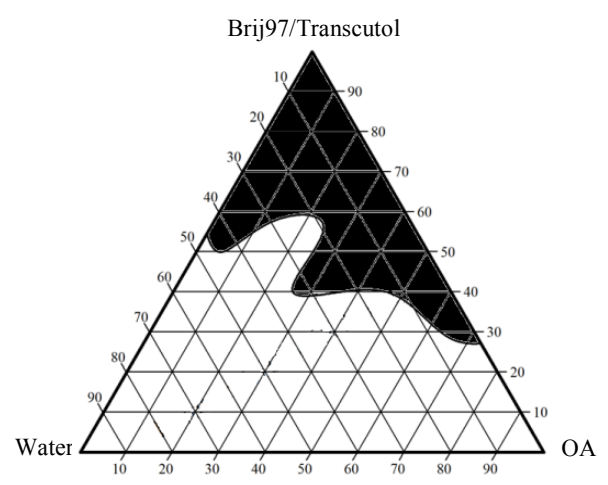

(c)

Figure 5. Pseudo-ternary phase diagrams composed of OA/Brij 97/Transcutol/water (a) $\mathrm{K}_{\mathrm{m}} 1: 1$, (b) $\mathrm{K}_{\mathrm{m}}$ 2:1 and (c) $\mathrm{K}_{\mathrm{m}} 3: 1$

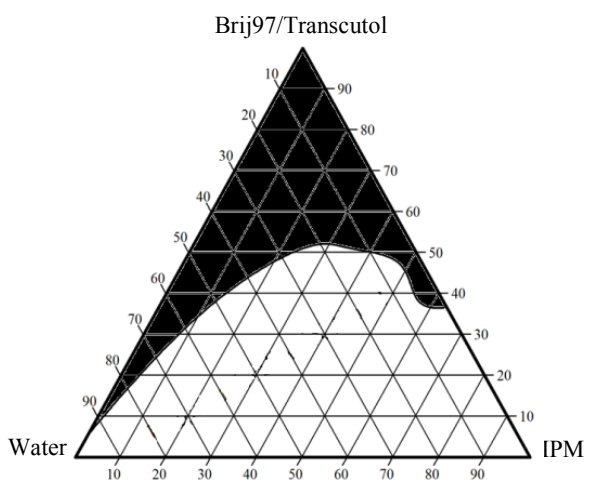

(a)

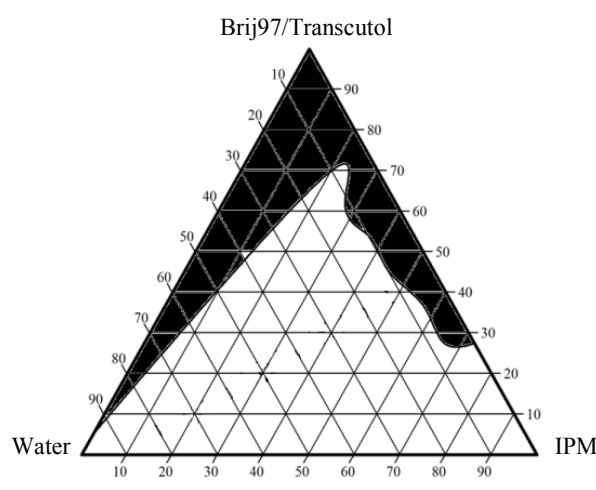

(b)

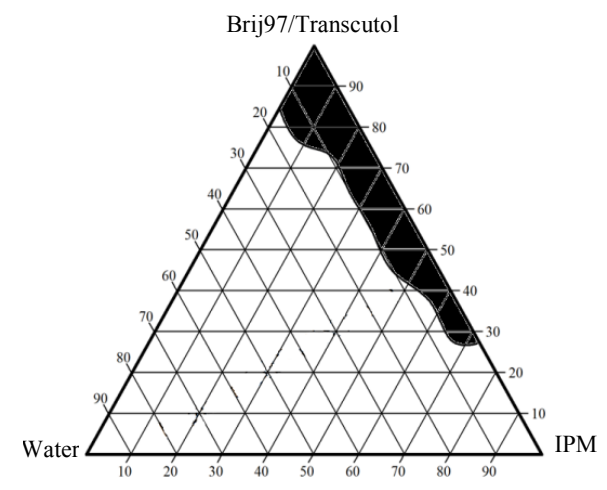

(c)

Figure 6. Pseudo-ternary phase diagrams composed of IPM/Brij 97/Transcutol/water (a) $K_{m} 1: 1$, (b) $K_{m} 2: 1$ and (c) $\mathrm{K}_{\mathrm{m}} 3: 1$

A system which comprises of IPM (oil), Brij 97 (surfactant), transcutol (co-surfactant) and water (aqueous) shows a high stability and a broad microemulsion area (Figure 7) thus, it is potential to utilize in various applications especially in pharmaceutical application due to their safe and pharmaceutical accepted components.

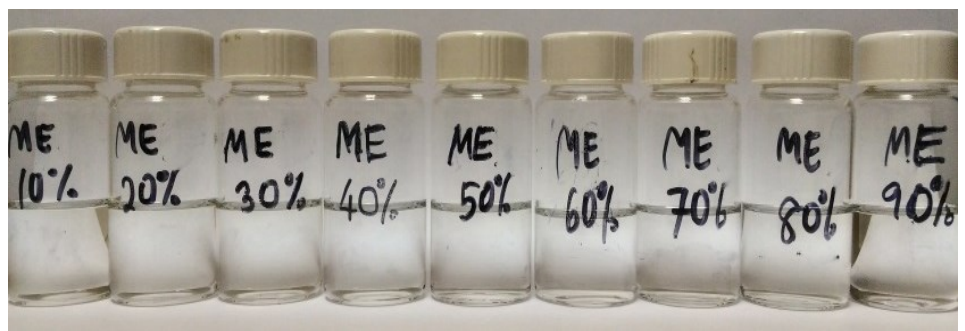

Figure 7. The clear and isotropic of IPM/Brij 97/Transcutol/Water microemulsion system 


\section{Conclusion}

A total of 18 phase diagrams were constructed successfully and each formulation gives significant effect on the area of microemulsion region. This study gives two conclusions that could make. First, oleic acid based system (OA/Brij 97/PEG 400/Water, OA/Brij 97/PG/Water, and OA/Brij 97/Transcutol/Water) could not form a large region of microemulsions. Therefore, IPM shows a better choice in order to get a larger area of microemulsion with a higher concentration of water with transition phase from water-in-oil (w/o) to oil-in-water (o/w). Second, the effect of a cosurfactant depends on its chain length, where only appropriate chain lengths are suitable for good microemulsion formation [14]. PEG 400 (long chain), transcutol (medium chain) and propylene glycol (short chain) were used in this study to evaluate the effect of co-surfactants on the formation of microemulsions. In this case, medium chain length is the most suitable co-surfactant in combination with the single-chain surfactant, Brij 97 followed by short and long chain length.

\section{Acknowledgement}

The authors would like to thank Universiti Kebangsaan Malaysia (UKM) and the Malaysian Ministry of Science, Technology, and Innovation (MOSTI) for financial support through the Research University Grant Scheme (GUP2017-087) and Fundamental Research Grant Scheme (FRGS/1/2013/SG01/UKM/03/1).

\section{References}

1. Sahu, G. K., Sharma, H., Gupta, A. and Kaur, C. D. (2015). Advancements in microemulsion based drug delivery systems for better therapeutic effects. International Journal of Pharmaceutical Sciences and Developmental Research, 1: $8-15$.

2. Ritika, SL, H. \& Geeta, A. 2012. Review Article Microemulsion System in Role of Expedient Vehicle for Dermal Application. Journal of Drug Delivery and Therapeutics, 2(4), 23-28.

3. Ghosh, P. and Murthy, R. (2006). Microemulsions: A potential drug delivery system. Current Drug Delivery, 3(2): $167-180$.

4. Muzaffar, F., Singh, U. K. and Chauhan, L. (2013). Review on microemulsion as futuristic drug delivery. International Journal of Pharmacy and Pharmaceutical Sciences, 5(3): 39 - 53.

5. Hoar, T. P. and Schulman, J. H. (1943). Transparent water-in-oil dispersions: The oleopathic hydro-micelle. Nature, 152: $102-103$.

6. Talegaonkar, S., Azeem, A., Ahmad, F. J., Khar, R. K., Pathan, S. A. and Khan, Z. I. (2008). Microemulsions: A novel approach to enhanced drug delivery. Recent Patents on Drug Delivery \& Formulation, 2(3): 238 - 257.

7. Prince, L. M. (1967). A theory of aqueous emulsions I. Negative interfacial tension at the oil/water interface. Journal of Colloid and Interface Science, 23(2): 165 - 173.

8. Kumar, A., Kushwaha, V. and Sharma, P. K. (2014). Pharmaceutical microemulsion: Formulation, characterization and drug deliveries across skin. International Journal of Drug Development and Research, 6(1): $1-21$.

9. Grampurohit, N., Ravikumar, P. and Mallya, R. (2011). Microemulsions for topical use- A review. Indian Journal of Pharmaceutical Education and Research, 45(1): 100 - 107.

10. Hathout, R. M., Woodman, T. J., Mansour, S., Mortada, N. D., Geneidi, A. S. and Guy, R. H. (2010). Microemulsion formulations for the transdermal delivery of testosterone. European Journal of Pharmaceutical Sciences, 40(3): $188-196$.

11. Ramli, S., Mohd Ja'afar, S., Abd Sisak, M. A., Zainuddin, N. and Rahman, I. A. (2015). Formulation and physical characterization of microemulsions based carboxymethyl cellulose as vitamin $\mathrm{C}$ carrier. Malaysian Journal of Analytical Sciences, 19(1): 275 - 283.

12. Lawrence, M. J. and Rees, G. D. (2012). Microemulsion-based media as novel drug delivery systems. Advanced Drug Delivery Reviews, 64: 175 - 193.

13. Huang, C.-T., Tsai, M.-J., Lin, Y.-H., Fu, Y.-S., Huang, Y.-B., Tsai, Y.-H. and Wu, P.-C. (2013). Effect of microemulsions on transdermal delivery of citalopram: optimization studies using mixture design and response surface methodology. International Journal of Nanomedicine, 8: 2295 - 2304.

14. Al Abood, R. M., Talegaonkar, S., Tariq, M. and Ahmad, F. J. (2013). Microemulsion as a tool for the transdermal delivery of ondansetron for the treatment of chemotherapy induced nausea and vomiting. Colloids 


\section{Muhammad Asri et al: STUDY ON THE EFFECT OF OIL PHASE AND CO-SURFACTANT ON MICROEMULSION SYSTEMS}

and surfaces. B, Biointerfaces, 101: $143-151$.

15. Djekic, L. and Primorac, M. (2008). The influence of cosurfactants and oils on the formation of pharmaceutical microemulsions based on PEG-8 caprylic/capric glycerides. International Journal of Pharmaceutics, 352(1-2): $231-239$.

16. Abd-Allah, F. I., Dawaba, H. M. and Ahmed, A. M. S. (2010). Development of a microemulsion-based formulation to improve the availability of poorly water-soluble drug. Drug Discoveries and Therapeutics, 4(4): $257-266$.

17. Yin, Y. M., Cui, F. De, Mu, C. F., Choi, M. K., Kim, J. S., Chung, S. J., Shim, C. K. (2009). Docetaxel microemulsion for enhanced oral bioavailability: Preparation and in vitro and in vivo evaluation. Journal of Controlled Release, 140(2): 86 - 94.

18. Santos, P., Watkinson, A. C., Hadgraft, J. and Lane, M. E. (2008). Application of microemulsions in dermal and transdermal drug delivery. Skin Pharmacology and Physiology, 21(5): 246 - 259. 